\title{
Comparative Analysis of Indirect ELISA and Real Time PCR for the Detection of Anaplasma Marginale in Buffalo, Cattle and Sheep in District Peshawar and Lakki Marwat, Pakistan
}

\section{Anwar Ali Turi ${ }^{1}$, Abdur Rahman ${ }^{2}$, Ijaz Ali ${ }^{1}$, Rafiullah ${ }^{1}$, Abdul Sajid ${ }^{3}$, Khalid Khan ${ }^{1}$,Imtiaz Ali Shah ${ }^{1}$, Muhammad Asif Gondal $^{4}$, Ameen-ur-Rashid ${ }^{4}$, Siraj Ahmed ${ }^{5}$, Inamullah Wazir ${ }^{6}$, Sohail Khan ${ }^{1}$, Arifullah KhaN ${ }^{2}$}

${ }^{1}$ Veterinary Research Institute Peshawar; ${ }^{2}$ Faculty of Animal Husbandry and Veterinary Sciences, The University of Agriculture, Peshawar; ${ }^{3}$ The Abdul Wali Khan University Mardan; ${ }^{4}$ Department of Biosciences, COMSATS Institute of Information Technology, Islamabad; ${ }^{5}$ Department of Microbiology, Abasyn University Peshawar; ${ }^{6}$ Institute of Microbiology, The University of Agriculture, Faisalabad, Pakistan.

\begin{abstract}
Anaplasmosis is disease of livestock having pandemic in nature. In the present study the specificity and sensitivity of i-ELISA and RT PCR was investigated in the samples collected from District Peshawar and Lakki Marwat. A total of 900 samples were collected from three species, Cattle, Buffalo and Sheep from two transects Peshawar and Lakki Marwat for determination of rate of Anaplasma marginale through i-ELISA and RT PCR. Overall rate for Anaplasmosis was 37.7\% (339/900) for all three techniques, whereas techniques wise the rate of Anaplasma marginale was $28.7 \%$ and $34.8 \%$ through i-ELISA and Real-time PCR, respectively. Majority of the Cattle (41.6 \%) were found positive for $A$. marginale as compared to $23.7 \%$ and $16.2 \%$ in Sheep and Buffalo respectively. Transects were significantly different at $\mathrm{P}<0.05$ in term of rate of $A$. marginale. Transect wise distribution of anaplasmosis was higher in Lakki Marwat (41.5\%) as compared to Peshawar (30\%). Gender wise rate was higher in female through i-ELISA (57.96\%) and RT PCR (64.33\%) as compared to male individuals having $16.27 \%$ and $23.25 \%$ rate, respectively. A significant difference was found in seasonality of tick infestation, with the high infestations in summer as compare to winter.
\end{abstract}

Keywords $\mid$ Anaplasma marginale, Cattle, Buffalo, Sheep, Peshawar, Lakki Marwat, i-ELISA, RT PCR

\footnotetext{
Editor | Muhammad Nauman Zahid, Quality Operations Laboratory, University of Veterinary and Animal Sciences, Lahore, Pakistan.

Received | December 15, 2017 Accepted | January 13, 2018; Published | April 19, 2018

*Correspondence | Ameen-ur-Rashid, Department of Biosciences, COMSATS Institute of Information Technology, Islamabad, Pakistan; Email: ameenurrasheed@yahoo.com

Citation | Turi AA, Rahman A, Ali I, Rafiullah, Sajid A, Khan K, Shah IA, Gondal MA, Rashid AU, Ahmed S, Wazir I, Khan S, Khan A (2018). Comparative analysis of indirect elisa and real time pcr for the detection of anaplasma marginale in buffalo, cattle and sheep in district peshawar and lakki marwat, Pakistan. $\mathrm{S}$. Asian J. Life Sci. 6(1): 1-6.
}

DOI | http://dx.doi.org/10.17582/journal.sajls/2018/6.1.1.6

ISSN | 2311-0589

Copyright $\odot 2018$ Rashid et al. This is an open access article distributed under the Creative Commons Attribution License, which permits unrestricted use, distribution, and reproduction in any medium, provided the original work is properly cited.

\section{INTRODUCTION}

$\mathrm{L}$ ivestock plays a significant role in the economy of the country. The share of livestock to the agriculture is about 55.4 percent and to the GDP it was 11.9 percent recorded during the year 2012-13 (Economic Survey of Pakistan, 2012-13). To increase the Cattle production it was not followed by progress in hygienic status of animals and this will led to the incidence of diseases in animals and one of them are tick borne diseases, among these diseases Babesiosis, Anaplasmosis,
Theileriasis and Ehrlichiosis (Simuunza et al., 2011). The genus Anaplasma was described for the first time by Sir Arnold Theiler,who first documented that "marginal points" were found responsible to cause some specific disease (Theiler, 1910).Tick- Borne Diseases (TBDs). In livestock, Anaplasmosis is mainly transmitted by mechanical way such as by biting flies, lice, and biologically by different tick species and also by fomites. In livestock, there are a several Tabanus species (horseflies) and also several mosquitoes have been confirmed in experimental transmission of Anaplasmosis. It has also been observed that adult ticks 
(Dermacentor occidentalis) are mainly responsible for Transmission of $A$. marginale in livestock, since this adults species (Dermacentor occidentalis) usually suck the blood from Cattle and deer, it is likely that there is inter-transmission occur deer and deer, deer and Cattle, Cattle and deer. (Oseboldet al., 1962).

In Cattle, $A$. marginale occurs in acute and sub-acute forms, however sub-clinical infections are common. In animals up to one year of age this diseases occur in sub-clinical form, while in animals from 12- 24 months old the disease is less low scale as compare to old aged animals where it causes death on large scale (Potgieter et al., 2004).

In tropical regions Anaplasmosis causes major economic losses to the livestock owners in shape of mortality in domestic animals and also causes health related problems such as low production and poor growth rate (Jonssonet al., 2008; Alfredo et al., 2005). It is suspected that Tickborne diseases are main cause for fifty percent Cattle mortality (Martins et al., 2008). In livestock these haemoparasitic diseases make great loss of about 250 million, and play main constraint in production and development of livestock sector in many developing countries of world (Radostits et al., 2000).

This study was conducted to investigate the rate of $A$. marginale in District Peshawar and Lakki Marwat by using Sero-detection of Anaplasma by Ind.ELISA (Indirect Enzyme-Linked Immuno-Sorbent Assay) and Molecular detection of Anaplasma by RT PCR in Cattle, Buffalo and Sheep.

\section{MATERIALS AND METHODS}

In the present study a total of 900 blood samples (300 each species) were collected from each species of Cattle, Buffalo and Sheep. These samples were collected from District Peshawar and Lakki Marwat and transported to the Molecular Laboratory of Center of Parasitology and Poultry under refrigeration. These samples were screened through Ind.ELISA and RT PCR in order to know the standard diagnostic technique in order to avoid the false positive or negative results.

A volume of $5 \mathrm{ml}$ blood were collected from each selected animal via jugular vein in commercially available jell added vaccutanier for Ind. ELISA and EDTA added vaccutanier for DNA extraction for RT PCR through using disposable sterilized plastic syringes.

\section{INDIRECT ELISA}

Recognition of $A$. marginale in Cattle, Buffalo and Sheep was carried out through Indirect ELISA following the manufacturer's (svanova ${ }^{\circledR}$ ) protocol.

\section{Real-Time Polymerase Chain Reaction}

For Simultaneous Detection and Quantification of $A n a-$ plasma Marginale in Cattle, Buffalo and Sheep Real-Time Polymerase Chain Reaction (R-T PCR) was performed.

\section{Statistical Analysis}

All the data was stored in Microsoft Excel and descriptive statistics was carried out in excel and export to Statistical program. Results were presented as counts and percentages of positive samples. Significant test was calculated for the various parameters using the Fits a variance components model by residual maximum likelihood (Reml) in Genstat software. Correlations of various parameters were determined by Pearson correlations.

\section{RESULTS}

Overall Rate of $A$. Marginale in both Districts In the present study, the overall rate of $A$. marginale in different livestock species was summarized in the Table 1.

Table 1: Overall rate of $A$. marginale

\begin{tabular}{|c|c|c|}
\hline Total samples & \multicolumn{2}{|c|}{ Positive\% } \\
\hline \multirow[t]{2}{*}{900} & Ind.ELISA & RT PCR \\
\hline & $258(28.7 \%)$ & $313(34.8 \%)$ \\
\hline
\end{tabular}

\section{Transect wise Rate of $A$. marginale}

Transect wise the highest rate was recorded in Lakki Marwat with $41.5 \%$ as compared with Peshawar with $30 \% \mathrm{Ta}-$ ble 2 .

Table 2: Transect-wise Rate of $A$. marginale

\begin{tabular}{ll} 
Transects & \\
Lakki Marwat & Peshawar \\
$41.5 \%$ & $30 \%$ \\
\hline
\end{tabular}

Area Wise Rate of $A$. MARginale

On the basis of i-ELISA the highest rate of rate was observed in Lakki-2 (39.4\%) followed by Pesh-3 (30.7\%) and Lakki-1 (30\%), while in Peshawar i.e.Pesh-4, Pesh-2 and Pesh-1 were (18.7\%), (17.4\%) and (16\%) respectively Table 3 .

On real time RT PCR the rate of $A$. marginale in Lakki-2 (47.7\%) followed Pesh-3 (40\%) and Lakki-1 (30.7\%). While in Pesh-3, the rate was $87 \%$ higher recorded for Real-Time RT PCR as compared to the rest of the three areas in the Peshawar transect. This table also depicted that the overall rate of Real-Time RT PCR is $21 \%$ higher in term of positive cases then Indirect ELISA. 
Table 3: Area wise Rate of $A$. marginale in Peshawar and Lakki Marwat.

\begin{tabular}{|lllll|}
\hline Area & $\begin{array}{l}\text { No of } \\
\text { observation }\end{array}$ & $\begin{array}{l}\text { Ind.ELI- } \\
\text { SA(\%) }\end{array}$ & $\begin{array}{l}\text { RT PCR } \\
\text { (\%) }\end{array}$ & P.Value \\
\hline Pesh-1 & 75 & $11(15)$ & $16(21)$ & \\
\hline Pesh-2 & 75 & $12(16)$ & $16(21)$ & \\
\hline Pesh-3 & 75 & $23(31)$ & $30(40)$ & \\
\hline Pesh-4 & 75 & $13(17)$ & $16(21)$ & \\
\hline Total Pesh & 300 & $20 \%$ & $26 \%$ & $<0.001$ \\
\hline Lakki-1 & 300 & $81(30)$ & $92(31)$ & \\
\hline Lakki-2 & 300 & $118(39)$ & $143(48)$ & \\
\hline Total Lakki & 600 & $33.2 \%$ & $39.2 \%$ & $<0.001$ \\
\hline Total & 900 & $258(28.7)$ & $313(34.8)$ & \\
\hline
\end{tabular}

Transect were significantly different at $\mathrm{P}<0.001$ in term of rate of Anaplasmamarginale.

\section{Sex Wise Rate of $A$. marginale}

Table 4: Sex wise rate of $A$. marginale

$\begin{array}{lllll}\text { Test used } & \begin{array}{l}\text { No of } \\ \text { Observation }\end{array} & \begin{array}{l}\text { Male } \\ (\%)\end{array} & \begin{array}{l}\text { Female } \\ (\%)\end{array} & \begin{array}{l}\text { P. } \\ \text { Value }\end{array} \\ \text { Ind.ELISA } & 900 & \begin{array}{l}27 / 176 \\ (15.4)\end{array} & \begin{array}{l}231 / 724 \\ (31.9)\end{array} & \\ & & 35 / 176 & 278 / 724 & \\ \text { RT PCR } & 900 & (19.9) & (38.4) & \\ & & 26 / 176 & 218 / 724 & <0.001 \\ \text { Total } & & (14.8) & (30.2) & \\ & & \end{array}$

Transect were significantly different at $\mathrm{P}<0.001$ in term of rate of Anaplasmamarginale.

\section{Rate of Anaplasma marginale in Cattle}

Table 5: Specie wise rate of $A$. marginale in Cattle.

\begin{tabular}{lllll} 
Area & $\begin{array}{l}\text { No of } \\
\text { observation }\end{array}$ & $\begin{array}{l}\text { Ind.ELISA } \\
\text { (\%) }\end{array}$ & $\begin{array}{l}\text { RT. } \\
\text { PCR(\%) }\end{array}$ & P.Value \\
\hline Pesh-1 & 25 & $5(20)$ & $8(32)$ & \\
Pesh-2 & 25 & $4(16)$ & $6(24)$ & \\
\hline Pesh-3 & 25 & $10(40)$ & $12(48)$ & \\
\hline Pesh-4 & 25 & $9(36)$ & $10(40)$ & \\
Pesh & 100 & $28(\%)$ & $36(\%)$ & $<0.001$ \\
Lakki-1 & 100 & $40(40)$ & $45(45)$ & \\
Lakki-2 & 100 & $58(58)$ & $66(66)$ & \\
Lakki & 200 & $49(\%)$ & $55.5(\%)$ & $<0.001$ \\
Total & 300 & $126(42)$ & $147(49)$ & \\
Species wise there were significantly different at P $<0.001$ in \\
term of rate of Anaplasmamarginale.
\end{tabular}

Overall rate of $A$. marginale in Cattle is explained in fol- lowing table. Overall rate of $A$. marginale in Cattle was (42\%) and (49\%) for Ind.ELISA and Real-Time PCR respectively. On Indirect ELISA technique, in Lakki-2 the rate was (45\%) higher for Ind.ELISA as compare to the Lakki-1 and Pesh-3 in the two transects. Similarly on Real-Time RT PCR, the Cattle of Lakki-2 showed high rate of rate of $A$. marginale which was (66\%) followed by Pesh3 (48\%) Table 5.

\section{Sex Wise Rate of $A$. marginale in Cattle}

Sex-wise rate of $A$ marginale for Ind.ELISA was (30.2\%) higher in female then the rest of the areas. In male the rate was recorded (50\%) in Pesh-3 for Real-Time RT PCR, whereas in Lakki-2 the highest rate was recorded in female with (72\%) and in male it was (50\%) in Pesh-3 Table 6.

Table 6: Sex-wise rate of $A$. marginale in Cattle

\begin{tabular}{|c|c|c|c|c|}
\hline Areas & $\begin{array}{l}\text { Indnd. } \\
\text { ELISA(\%) }\end{array}$ & $\begin{array}{l}\text { ๆ Ind. } \\
\text { ELISA(\%) }\end{array}$ & $\begin{array}{l}{ }^{7} \mathbf{R T} \\
\text { PCR(\%) }\end{array}$ & 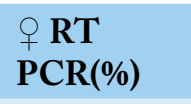 \\
\hline Pesh-1 & $1 / 4(25)$ & 4/21(19) & $1 / 4(25)$ & $7 / 21(33)$ \\
\hline Pesh-2 & $1 / 5(20)$ & $3 / 20(15)$ & $1 / 5(20)$ & $5 / 20(25)$ \\
\hline Pesh-3 & $2 / 4(50)$ & $8 / 21(38)$ & $2 / 4(50)$ & $10 / 21(48)$ \\
\hline Pesh-4 & $1 / 4(25)$ & $8 / 21(38)$ & $1 / 4(25)$ & $9 / 21(43)$ \\
\hline Total & $5 / 17(29)$ & $23 / 83(28)$ & $5 / 17(29)$ & $31 / 83(37)$ \\
\hline Lakki-1 & $3 / 26(12)$ & $37 / 74(50)$ & $4 / 26(16)$ & $41 / 74(55)$ \\
\hline Lakki-2 & $4 / 17(24)$ & $54 / 83(65)$ & $6 / 17(36)$ & $60 / 83(72)$ \\
\hline Total & $7 / 43(16)$ & $\begin{array}{l}91 / 157 \\
(58)\end{array}$ & $\begin{array}{l}10 / 43 \\
(23)\end{array}$ & $127 / 157(81)$ \\
\hline Total & $12 / 60(20)$ & $\begin{array}{l}114 / 240 \\
(48)\end{array}$ & $\begin{array}{l}15 / 60 \\
(25)\end{array}$ & $157 / 240(66)$ \\
\hline
\end{tabular}

Sex was significantly different at $\mathrm{P}<0.001$ in term of positivity, for both tests in female Cattle rate were more than in male.

\section{Rate of ANAPLasma marginale in Buffalo}

Table 7: Specie-wise rate of $A$. marginale in Buffalo

\begin{tabular}{|lllll|}
\hline Area & $\begin{array}{l}\text { No of } \\
\text { observation }\end{array}$ & $\begin{array}{l}\text { Ind. ELISA } \\
(\mathbf{\%})\end{array}$ & $\begin{array}{l}\text { RT PCR } \\
\mathbf{( \% )}\end{array}$ & P. Value \\
\hline Pesh-1 & 25 & $2(8)$ & $3(12)$ & \\
\hline Pesh-2 & 25 & $3(12)$ & $5(20)$ & \\
\hline Pesh-3 & 25 & $6(24)$ & $8(32)$ & \\
\hline Pesh-4 & 25 & $1(4)$ & $3(12)$ & \\
\hline Total & 100 & $12(12)$ & $19(19)$ & $<0.001$ \\
\hline Lakki-1 & 100 & $16(16)$ & $20(20)$ & \\
\hline Lakki-2 & 100 & $21(21)$ & $31(31)$ & \\
Total & 200 & $37(18.5)$ & $51(25.5)$ & $<0.001$ \\
\hline G. Total & 300 & $49(16.3)$ & $70(23.4)$ & \\
\hline
\end{tabular}


The overall rate of $A$. marginale in Buffalo for Ind. ELISA and Real-Time PCR were recorded as (16.3\%) and (23.3\%) respectively. Area wise the highest rate of Anaplasma marginale on Ind.ELISA, was the highest in Pesh-3 (24\%) followed by Lakki-2 (21\%), Similarly on Real-Time PCR, the Cattleof Pesh-3 showed high rate of rate of $A$. marginale which was 32\% followed by Lakki-2 31\% Table 7.

Sex Wise Rate of Anaplasma marginale in Buffalo On Ind.ELISA, the male Buffalo of Pesh-3 showed higher rate of $A$. marginale which was $33.4 \%$ and in female Buffalo it was (23.2\%) similarly on Real-Time PCR the female Buffalo of Lakki-2 showed the higher rate of $A$. marginale which was $(35.7 \%)$ and in female Buffalo the rate was (36\%), While for male it was (33.4\%) in Pesh-3 Table 8.

Table 8: Sex wise Rate of $A$. marginale in Buffalo

\begin{tabular}{|c|c|c|c|c|}
\hline Areas & $\begin{array}{l}\text { ○lInd. } \\
\text { ELISA } \\
\text { (\%) }\end{array}$ & $\begin{array}{l}\text { q Ind. } \\
\text { ELISA } \\
\text { (\%) }\end{array}$ & $\begin{array}{l}{ }^{\lambda} \mathrm{RT} \\
\text { PCR (\%) }\end{array}$ & $\begin{array}{l}\text { P RT } \\
\text { PCR (\%) }\end{array}$ \\
\hline Pesh-1 & $0 / 5(0)$ & $12 / 20(0)$ & $1 / 5(20)$ & $2 / 20(10)$ \\
\hline Pesh-2 & $0 / 6(0)$ & $3 / 19(16)$ & $1 / 6(17)$ & $4 / 19(21)$ \\
\hline Pesh-3 & $1 / 3(34)$ & $5 / 22(23)$ & $1 / 3(34)$ & $7 / 22(32)$ \\
\hline Pesh-4 & $0 / 5(0)$ & $1 / 20(5)$ & $1 / 5(20)$ & $2 / 20(10)$ \\
\hline Total & 1/19(5) & 11/81(14) & $4 / 19(22)$ & 15/81(19) \\
\hline Lakki-1 & 1/9(11) & 15/91(17) & $1 / 9(11)$ & 19/91(21) \\
\hline Lakki-2 & 2/18(11) & 19/82(23) & 2/18(11) & $29 / 82(35)$ \\
\hline Total & $3 / 27(11)$ & $34 / 173(20)$ & $3 / 27(11)$ & $48 / 173(28)$ \\
\hline G.Total & 4/46(9) & $45 / 256(18)$ & 7/46(15) & $63 / 256(25)$ \\
\hline
\end{tabular}

\section{Rate of AnAPLasma marginale IN SHEeP}

Table 9: Specie-wise rate of $A$. marginale in Sheep

\begin{tabular}{lllll}
\hline Area & $\begin{array}{l}\text { No of } \\
\text { observation }\end{array}$ & $\begin{array}{l}\text { Ind.ELI- } \\
\text { SA(\%) }\end{array}$ & $\begin{array}{l}\text { RT PCR } \\
\text { (\%) }\end{array}$ & P.Value \\
\hline Pesh-1 & 25 & $4(16)$ & $5(20)$ & \\
\hline Pesh-2 & 25 & $5(20)$ & $5(20)$ & \\
\hline Pesh-3 & 25 & $7(28)$ & $10(40)$ & \\
\hline Pesh-4 & 25 & $3(12)$ & $3(12)$ & \\
\hline Pesh & 100 & $19(19)$ & $23(23)$ & $<0.001$ \\
\hline Lakki-1 & 100 & $25(25)$ & $27(27)$ & \\
\hline Lakki-2 & 100 & $39(39)$ & $46(46)$ & \\
\hline Lakki & 200 & $64(32)$ & $73(37)$ & $<0.001$ \\
\hline G.Total & 300 & $83(27.66)$ & $96(32.00)$ &
\end{tabular}

Overall rate of $A$. marginale in Sheep through Ind. ELISA and Real-Time RT PCR were recorded as (28\%) and
(32\%) respectively. While Area wise, on Indirect Ind.ELISA, the highest rate was observed in Lakki-2 (39\%) followed by Pesh-3 (28\%) Similarly on Real-Time PCR, the Cattle of Lakki-2 showed high rate of rate of $A$. marginale which was (46\%) followed by Pesh-3 (40\%) (Table 9).

\section{Sex Wise Rate of $A$. marginale in Sheep.}

Sex wise the highest rate of $A$. marginale for Indirect ELISA the highest rate was studied in female in Lakki-2 (49\%) and in male the rate was observed (25\%) in Pesh-4. For Real-Time RT PCR the highest rate was found in female and male in Lakki-2 with (57\%), (18\%) respectively.

\section{DISCUSSION}

Anaplasmosis is a tick-borne Hemorickettsial pathogen of livestock which is widespread in many parts of the world (Table 10).

Table 10: Sex-wise Rate of $A$. marginale in Sheep

\begin{tabular}{|c|c|c|c|c|}
\hline Areas & $\begin{array}{l}\text { o'Ind. } \\
\text { ELISA(\%) }\end{array}$ & $\begin{array}{l}\text { 任d. } \\
\text { ELISA(\%) }\end{array}$ & $\begin{array}{l}\text { ôT } \\
\text { PCR(\%) }\end{array}$ & $\begin{array}{l}\text { † RT } \\
\text { PCR(\%) }\end{array}$ \\
\hline Pesh-1 & 1/6(17) & 3/19(16) & $1 / 6(17)$ & $4 / 19(21)$ \\
\hline Pesh-2 & $1 / 6(17)$ & $4 / 19(21)$ & $1 / 6(17)$ & $4 / 19(21)$ \\
\hline Pesh-3 & $1 / 2(50)$ & $6 / 23(26)$ & $1 / 2(50)$ & $8 / 23(35)$ \\
\hline Pesh-4 & $1 / 4(25)$ & $2 / 21(9.5)$ & $1 / 4(25)$ & $2 / 21(10)$ \\
\hline Total & $4 / 18(22)$ & 15/82(18) & $5 / 18(28)$ & $31 / 82(38)$ \\
\hline Lakki-1 & $3 / 25(12)$ & $22 / 75(29)$ & $3 / 25(12)$ & $24 / 75(32)$ \\
\hline Lakki-2 & $4 / 28(14)$ & $35 / 72(49)$ & $5 / 28(18)$ & $41 / 72(57)$ \\
\hline Total & 7/53(13) & $57 / 147(39)$ & $8 / 53(15)$ & $65 / 147(44)$ \\
\hline G. Total & $11 / 71(16)$ & $72 / 229(44)$ & 13/71(18) & $91 / 229(40)$ \\
\hline
\end{tabular}

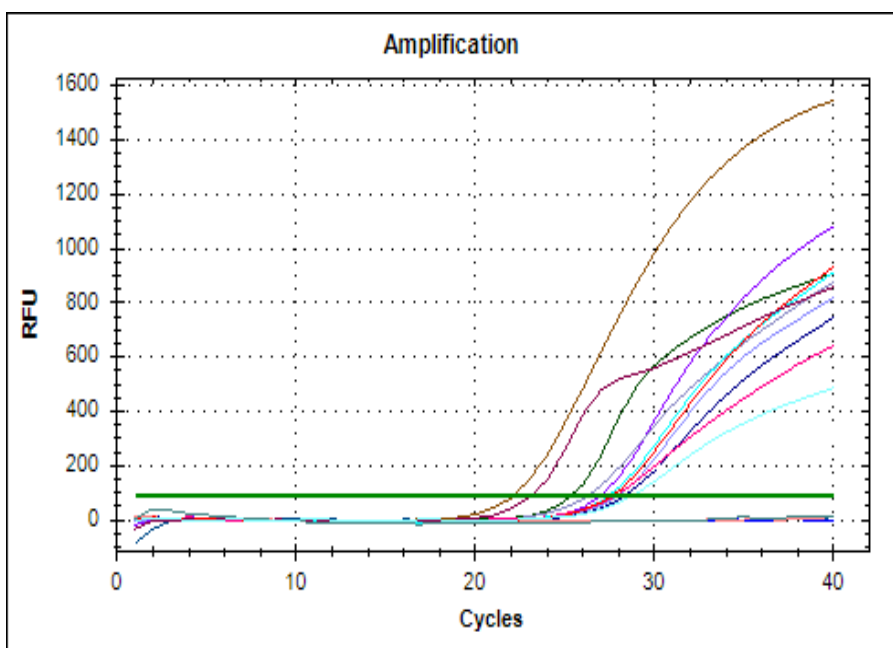

Figure 1: RT PCR DNA Amplification; The positive control quantified at 19 cycles. The graph represents the quantification cycles of samples with respect to positive and negative control. The earlier the quantification cycle comes the more is the infection. 


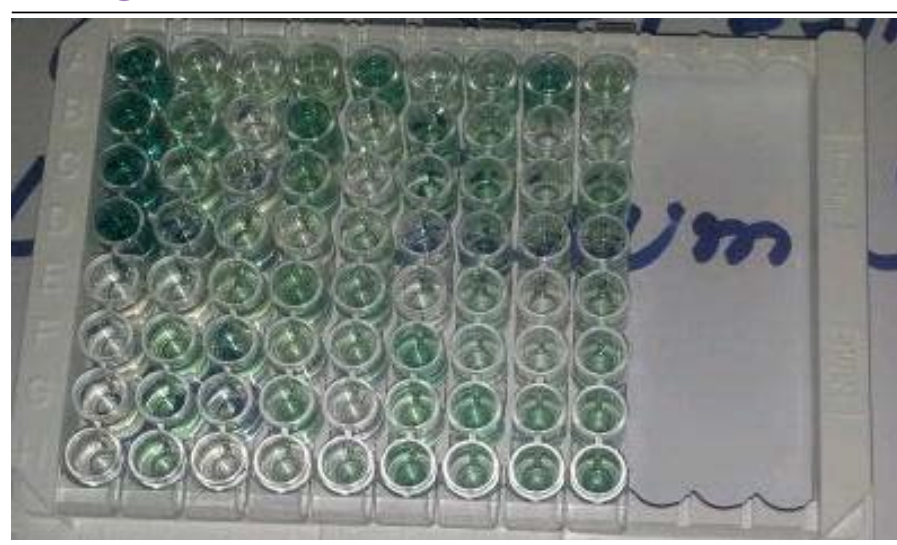

Figure 2: i-ELISA; The first four wells represent the positive control and the later represents the negative control, the intensity of the colour shows the titer of antibodies.

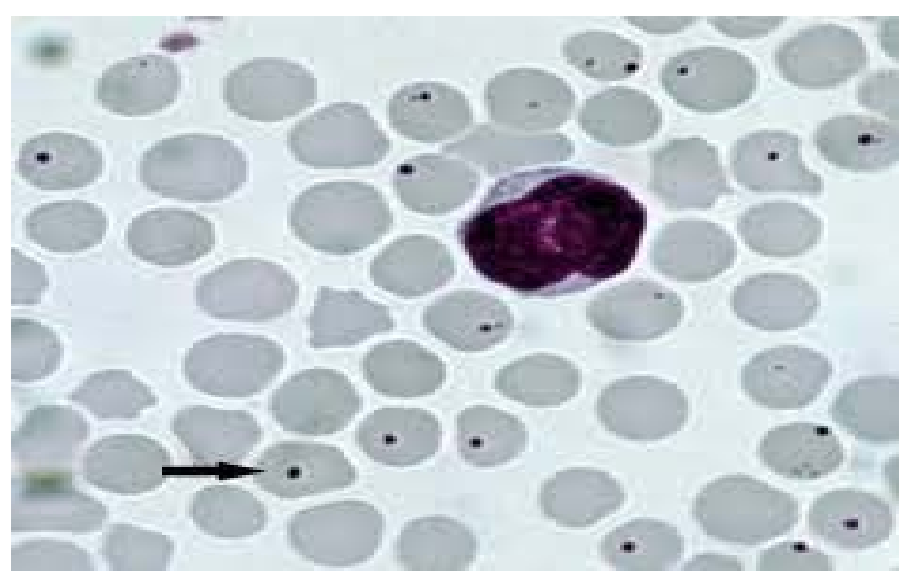

Figure 3: Anaplasma marginale visibility in Microscopy

A. marginale to certain extent is particularly related to ruminants, and commonly present in Cattle and Sheep, whereas some other ruminants may act as a reservoir for disease. The transmission of $A$. marginale takes place naturally by ticks, whereas the biting flies that have contamination with infected blood may be the source of mechanical transmission. Area which is free from ticks, transmission occurs through mechanical way.

The specie wise analysis of the data revealed that highest rate of disease was found in Cattle and Sheep, while lowest rate of disease was recorded in Buffaloes. A similar study was conducted by Khan et al. (2004) who reported that the rate of disease of protozoandiseases in Buffaloes and Cattle were $27.69 \%$ and $16.12 \%$, respectively. This may be justified as that the immune system of the Buffalos are stronger than Cattle.

The technique wise analysis of data in the both districts reflects that via Indirect ELISA the highest rate of disease occur in Lakki-2 (39\%) while the lowest was in Pesh-1 (16\%). The results obtained from Real-Time PCR showed that highest rate of disease occur in Lakki-2 (43\%) while the lowest was in Pesh-1, Pesh-2 and Pesh-4 with (21.4\%).
The comparative analysis of techniques showed that $\mathrm{Re}-$ al-Time PCR is more sensitive of all techniques used. Similarly a study was conducted Carelli et al. (2007) who reported that Real-Time PCR is the more sensitive technique. They further explained that Real-Time PCR is the more specific in a sense that it produces the same results in multiple runs and never confused with other haemoparasites which are antigenically related $A$. marginale.

Transect wise analysis of the present data explained that maximum rate of disease of $A$. marginale was present in district Lakki Marwat while lowest was in district Peshawar. This area wise difference is justified as Lakki Marwat as compare to Peshawar comparatively have high temperature throughout the year which directly affected the immune system of the animal which remain Immuno compromised and more susceptible for the disease. Furthermore the socioeconomic statuses of the farmers of these areas are not good and farmers do not have cemented farms and unaware of the managemental practices and control measures about the Tick Born Diseases. Area wise difference in rate of disease of $A$. marginale is also supported by the findings of Kocan et al. (2003).

Gender wise rate was higher in female through Ind.ELISA (57.96\%) and RT PCR (64.33\%) as compared to male individuals having $16.27 \%$ and $23.25 \%$ rate, respectively. These findings of the author are supported by khan et al, (2012) who reported the highest rate of disease in female (26\%) as compare rate of disease in male (17\%). However Antonio et al. (2011) reported that there is no significance relationship of anaplasmosis with sex.

\section{CONCLUSION}

Overall area-wise prevalence of $A$. marginale was recorded higher in samples collected from District Lakki Marwat as compare to District Peshawar, Khyber Pakhtunkhwa. An overall gender wise higher prevalence was recorded in female as compare to male for all the tested samples.Species wise prevalence was higher in Cattle (49\%) followed by Sheep (32\%) and Buffalo (23\%). The minimum prevalence of $A$. marginale was recorded in the areas where proper hygienic measure like spraying, dipping and cleanliness were ensured as compare to those in which proper managemental practices were not adopted. Real-Time PCR was observed to be more sensitive technique for detection of $A$. marginale among all the samples collected from Cattle, Sheep and Buffalo as compare to Indirect ELISA and $\mathrm{Mi}^{-}$ croscopy.

\section{RECOMMENDATIONS}

Keeping in view the facts and findings of the present study, 
it is recommended that; Measures should be taken to develop awareness among the farming community about the economic importance, control, prevention and diagnoses of tick borne diseases. Through molecular techniques, the tick strains infesting the local farm animals should be studied and differentiated through characterization and phylogenetic analyses as per recommendation of FAO. All species of Livestock kept in other transects should be thoroughly studied on these lines to have a real picture of the disease incidence of $A$. marginale infection in particular and Tick borne Diseases in general. The local strains of the infectious agents should be identified and characterized through molecular techniques. Measures should be taken to develop viccinal strains against anaplasmosis and other Tick borne diseases to have active prophylaxis strategies through active immunization of livestock.

\section{ACKNOWLEDGEMENTS}

Contributions of all the authors are highly acknowledged.

\section{CONFLICT OF INTEREST}

There was no conflict of interest in this research among any author.

\section{AUTHORS CONTRIBUTION}

Anwar Ali Turi, Abdur Rehman, Ijaz Ali and Khalid Khan conceived the idea. Rafiullah, Arifullah Khan, Sohail Ahmed and Imanullah Wazir collected samples. Anwar Ali Turi conducted whole study and trials with the help of Imtiaz Ali Shah, Siraj Ahmed and Abdul Sajid. Ameen ur Rashid has helped in write up, review and has done correspondence. Muhammad Asif Gondal has reviewed the research paper.

\section{REFERENCES}

- Alfredo AAN (2005). Serological survey of Babesiabovis and Anaplasma marginale in Cattle in Tete province, Mozambique. Trop. Anim. Health. Prod. 37(2):121-131. https://doi.org/10.1023/B:TROP.0000048513.80797.97

- Antonio AMT, JB da Silva, FJM da Silva, MS Pires, CD Baldani, CO Soares, CL Massard, AH da Fonseca (2011). Seroprevalence of $\mathrm{IgG}$ antibodies against Anaplasma marginale in Cattle from south Mozambique. Rev. Bras. Para. Vet. Jaboticabal. 20(4) 318-324. ISSN 1984-2961.

- Carelli GN, Decaro A, Lorusso G, Elia E, Lorusso V, Mari L, Ceci C, Buonavoglia (2007). Detection and quantification of Anaplasma marginale DNA in blood samples of cattle by real-time PCR. Vet. Mic. 124(1-2):107-14. https://doi. org/10.1016/j.vetmic.2007.03.022. http://www.finance.gov. pk/survey/chapters_13/02-Agriculture.pdf

- Jonsson NN, RE Bock, WK Jorgensen (2008). Productivity and health effects of Anaplasmosis and Babesiosis on Bosindicus Cattle and their crosses, and the effects of differing intensity of tick control in Australia. Vet. Para. 155:1: 1-9. https://doi. org/10.1016/j.vetpar.2008.03.022

- Khan MQ, A Zahoor, M Jahangir, MA Mirza (2004). Prevalence of blood parasites in Cattle and Buffaloes. Pak. Vet. J. 24: 193-195.

- Kocan KM, DL Fuente, AA Guglielmone, RD Melendez (2003). Antigens and alternatives for control of Anaplasma marginale infection in Cattle. Clin. Micro. Rev.16: 698-712 https://doi.org/10.1128/CMR.16.4.698-712.2003.

- Martins TM (2008). Detection of bovine Babesiosis in Mozambique by a novel semi nested hot-start PCR method. Vet. Para. 153(3-4): 225-230. https://doi.org/10.1016/j. vetpar.2008.01.037

- Osebold JW, JF Christensen, WM Longhurst, MN Rosen (1962). Latent Anaplasma marginale infection in wild deer demonstrated by calf inoculations. Cornell Vet. 49: 97-115.

- Potgieter FT, WH Stoltsz (2004). Bovine Anaplasmosis, in Infectious diseases of livestock, 2nd Edi. edited by J.A.W. Coetzer \& R.C. Tustin. Cape Town: Oxford.

- Radostits OM, CC Gay, DC Blood, KW Hinchcliff (2000). Veterinary Medicine. A Textbook of the Diseases of Cattle, Sheep, Pigs, Goats and Horses, 9th Ed. W.B. Saunders, Philadelphia ISBN 0702025399.

- Simuunza M (2011). Epidemiological analysis of tick-borne diseases in Zambia. Vet. Para. 175(3-4): 331-342. https:// doi.org/10.1016/j.vetpar.2010.09.027

- Theiler A (1910). Gall sickness of South Africa (anaplasmosis of Cattle). J. Comp. Pathol. Ther. 23: 98-115. https://doi. org/10.1016/S0368-1742(10)80028-1 